\title{
The Effect of Cost Categories and the Origin of their stickiness on Earnings Forecast: A Comparative Study
}

\author{
Ali Shirzad \\ Ph.D. Student in Accounting, School of Economics and Administrative Sciences, \\ Ferdowsi University of Mashhad, Mashhad, Iran. \\ Email: alishirzad@mail.um.ac.ir

\section{Mohammad Javad Saei ${ }^{1 *}$} \\ Assistant Professor of Accounting, School of Economics and Administrative Sciences, \\ Ferdowsi University of Mashhad, Mashhad, Iran. \\ Corresponding Author: Mohammad Javad Saei \\ Phone: +989153114339 \\ Email:mj-saei@um.ac.ir \\ Farzaneh Nassir Zadeh \\ Associate Professor of Accounting, School of Economics and Administrative Sciences, \\ Ferdowsi University of Mashhad, Mashhad, Iran. \\ Email: nasirzadeh@um.ac.ir
}

\section{Hassan Yazdifar}

Professor of Accounting and Head of Accounting, Finance and Economics Department, Bournemouth University, England

Email: hyazdifar@bournemouth.ac.uk

\footnotetext{
${ }^{1}$ Corresponding Author: Mohammad Javad Saei, School of Economics and Administrative Sciences,
} Ferdowsi University of Mashhad, Mashhad, Iran. Phone: +989153114339, Email: mj-saei@um.ac.ir 


\title{
The Effect of Cost Categories and the Origin of their stickiness on Earnings Forecast: A Comparative Study
}

\begin{abstract}
The main aim of this study is to separate the origins of "selling, general, and administrative costs (SG\&A)" and "cost of goods sold (COGS)" stickiness, and investigate their sources effects on earnings forecast accuracy (EFA). In previous research, various micro and macro factors have been shown to affect asymmetric cost behavior. These factors are rooted in the industry and firm-specific characteristics or specific events, which may occur each year at national or international scales. In this study, in the first step, a new methodology is presented to separate the sources of cost stickiness, including a novel method for calculating cost stickiness for each firm-year. In the second step, we investigated the effect of each firm-year stickiness and each source of stickiness on the EFA. The statistical population of the study consisted of all companies listed on the Tehran Stock Exchange, from which 1080 observations in 2014-2018 period were selected and reviewed. Our results indicated that EFA has a negative and significant relationship with SG\&A and COGS stickiness, stickiness of each year and each company, but no significant relationship was found with stickiness of each industry. Our results demonstrated that the stickiness of SG\&A to COGS has a greater effect on the EFA. The findings suggest that the events of each year and the intra-organizational events of each company have a greater impact on cost behavior. Hence, it is necessary for managers and financial analysts to take into account each source of cost stickiness, especially year-specific events and firm-specific characteristics, and consider their effects in earnings forecast to improve their EFA.
\end{abstract}

Keywords: Cost stickiness, Cost categories, Earnings Forecast, Origin of cost stickiness.

JEL Classification: M41, G17 


\section{Introduction}

Over the past two decades, a growing body of accounting research has looked into the asymmetric response of costs to changes in activity levels. The results of these studies suggest that costs fall (rise) when the level of activities fall (rise), but the rate of costs reduction is less than the reduction in activities. In contrast, the rate of increase in costs is almost proportional to the improvement in the level of activities. This type of cost behavior is called cost stickiness. Anderson et al. (2003) were the first to focus on asymmetric SG\&A to illustrate that cost stickiness has a negative effect on the firm's current earnings. It is because sales shrinkage is not offset by a reduction in costs. In their view, senior managers have authority over SG\&A costs. By reviewing and criticizing traditional models of cost behavior, they presented a new model in which costs do not change relative to changes in the level of activities. Rather, changes are based on decisions made by managers. They declare that two main causes of cost stickiness are "the theory of manager's personal considerations" that serve personal interest and "the theory of adjusted costs ". According to the former theory, managers do not always make decisions that provide the best outcomes for shareholders. Managers tend to maximize their own interests and may therefore be reluctant to cut back on resources in order to prevent a power reduction. One of the consequences of opportunistic contracts is managerial empire, meaning that management tends to overgrow the company and maintain untapped resources in order to preserve and increase personal interests, including prestige, position, power, reward, and credibility.

According to "the theory of adjusted costs" or "cost adjustments", when demand for an organization's products and services falls, managers can eliminate redundant resources and 
adjust the associated costs. If decreased activity level is temporary, the cost adjustment and the subsequent increase (due to the raised activity level) will likely exceed the cost of retaining redundant resources that have been temporarily conserved. The resource adjustment costs may include severance payments to dismissed employees, assets disposal costs, and penalties for terminating contracts. In addition, if the demand for products keeps rising after the cost adjustment, the firm will incur costs such as acquiring new assets based on conditions set by the company, recruiting and training new employees and negotiating costs for signing new contracts. Therefore, costs are not only proportionate to the current level of sales, but also may be reliant on managers' expectations for future sales.

However, sometimes there are reasons other than the company level that complicates the adjustment of resources despite managers' pessimism about the company's future. In this study, these factors are divided into macro to micro levels. At the first level, there are macroeconomic factors stemming from global and national developments, which contribute to cost stickiness. For example, events such as war, tariff warfare, sanctions, or global political crises at the international arena and changes in domestic policies (including amendments of laws or changes in political drivers that are expected to alter corporate support) affect management behavior in handling cost and therefore stickiness at the macro level. Given that these factors may vary at different times, the time factor (year) has been used to differentiate their effects. At the second level of stickiness, we look into industry-level factors. The industry-specific characteristics such as operational and production environment, intensity of competition and cost structure in different industries are other variables that influence the degree of cost stickiness. At the third level, there are the factors related to the company, 
including the ability of managers to forecast future conditions and varying levels of risk aversion.

Identifying the source of these factors enables managers to make appropriate decisions regarding resource adjustment. By identifying and measuring the sources of cost stickiness, managers can clarify and evaluate their reasons for cost stickiness and non-adjustment of costs, improving the company's flexibility in the face of diminishing demand for its goods or services. This helps improve the company's accountability process. By knowing the cost behavior, company owners can also determine whether management is imposing unnecessary costs on the firm. It is also useful to ascertain the cost behavior of external users (such as analysts) who intend to evaluate the company's performance. Therefore, identifying the origin, can be effective in measuring and controlling the degree of cost stickiness and its consequences.

Based on the theoretical framework of financial reporting, cost segregation provides more comprehensive information on the behavior of different types of costs. When costs are considered as total costs, we can only judge the behavior of total costs at the time of the change in sales, while each type of cost may have different behaviors. Therefore, in this study, to further investigate the behavior of costs, costs are categorized based on function and examined. For this purpose, in this research, costs are divided into two groups: Selling, general, and administrative (SG\&A) and cost of goods sold (COGS).

As noted in a few numbers of previous researches, one of the major consequences of cost stickiness is its effect on the EFA. Most financial managers and analysts project earnings irrespective of the effects of cost stickiness on future expenses, which underline the EFA. However, they can forecast earnings more accurately by assessing the cost stickiness and the 
impact of its sources on future earnings. Therefore, as the second goal of this study, we consider the importance of accurate earnings forecast and its impact on users' decisions, and seek to investigate the effect of the degree of cost stickiness on EFA and measure the relative share of each stickiness source on EFA.

Therefore, the main contributions of this research to the literature on cost stickiness are:

1) Identifying, separating and measuring stickiness sources,

2) Examining the separate consequences and impacts of each cost stickiness source on EFA.

In the following, first, the theoretical foundations and research background are discussed and the hypotheses are proposed. Then the data are described and descriptive statistics are presented. In the next section, following the separation of cost stickiness sources, the impact of each source on the EFA is evaluated. Finally, the study results concluded and suggestions presented.

\section{Literature Review and Hypothesis Development}

According to previous research, multiple factors influence cost stickiness. Each of these factors are related to specific characteristics of each year [Lee et al. (2020), Awad and Awad (2015)], country [(Calleja et al. (2006), Byzalov \& Chen (2013), Banker \& Byzalov (2014), Kama \& Weiss (2013),], industry [Banker, Flasher \& Zhang (2014), Subramaniam et al. (2016)] and firm [Banker et al. (2014), Subramaniam et al. (2016), Dierynck \& Renders (2009), Kama and Weiss (2013), Hay et al. (2010), Banker et al. (2011) and Chen et al. (2011)]. For example, setting varying tariffs by the United States on European and Chinese goods in 2018 is one of the events that can affect the economies of the parties, the level of production and even the degree of cost stickiness in continental Europe, China and the United 
States. Moreover, the imposition of various economic sanctions against Iran affects GDP, sales and the degree of cost stickiness based on managers' optimism or pessimism about the country's economic future. Besides, a number of factors such as technology level, which is rooted in the development of a country, and industry membership, can affect the degree of cost stickiness. In addition, laws and regulations of each country, corporate governance, and a host of other factors can influence the degree of cost stickiness. Each of these sources can trigger cost stickiness, but as noted by researchers [(Calleja et al. (2006), Banker, Byzalov \& Chen (2013), Banker \& Byzalov (2014), Lee et al. (2020), Awad and Awad (2015)] identifying some of these factors could be ambiguous and increase the probability of errors in decisions. As mentioned earlier, in this study, the sources of stickiness are divided into three levels: year, industry and firm. Each of these three levels is discussed in detail below.

Certain global and local events alter the degree of cost stickiness. These factors can be provoked by special political or economies events such as sanctions, war, tariff warfare, elections and political instability. According to Anderson et al. (2003), management not only takes into account the specific characteristics of a company in declining demand, but also analyzes the economic development in the product market and economic conditions at the global scale. Managers tend to see demand reduction as temporary whenever they expect significant economic growth. War and sanctions can make managers pessimistic about the future and influence their decisions about resource adjustment. Lee et al. (2020) suggested that even by controlling company-level and country-level factors, the cost behavior asymmetry (cost stickiness) in election years will be greater than in non-election years. Economic sanctions are also one of the major tools for achieving political goals, which prompt economic and political instability, especially in sanctioned years. In recent years, multiple sanctions 
imposed on Iran have engendered serious economic problems, so that the production and sale of almost all industries have been adversely affected. Sanctions have always been a major hurdle to Iran's progress and development, which while hampering the introduction of modern technologies to Iran and reducing oil and non-oil exports, have rendered investors pessimistic about the country's economic future and managers disappointed with corporate futures. Economic sanctions, as economic and political destabilizers, will modify the asymmetric behavior of costs, and the asymmetric cost behavior and managers' pessimism about the company's future will exert a negative effect on the degree of cost stickiness.

The industry-specific characteristics affect costs adjustment when the scale of the company's activity is modified. These features can be split into two groups. The first group consists the intensity of assets and employees. The second group embraces other industryspecific characteristics such as operating and production environment, competition intensity, fixed and variable cost ratios, and supply chain. Anderson et al. (2003) contend assets and employees intensity as two main specific characteristics of the company that affect the adjustment of costs. It is assumed that the intensity of assets alters the adjustment of resources, because a decrease in assets is not commensurate with the decline in the company's activities. In firms with higher asset intensity, the costs associated with their resources, such as depreciation, repairs and maintenance costs will be higher, and failure to reduce costs relative to the level of activity will lead to cost stickiness. Therefore, assets have a huge bearing on cost stickiness because small companies usually hold less fixed assets. This indicates low costs associated with assets and when the level of activity shrinks, the stickiness in these companies will be lower. Employee intensity affects cost adjustment for three reasons. First, the layoffs of redundant workforce will impose additional costs on the firm, and managers will 
be worry about losing skilled, experienced, and loyal employees. Second, if demand for products rises, the firm will be forced to hire new employees, which will incur recruitment and training costs. Third, layoffs will dampen the morale of other employees and diminish productivity. A mixture of these factors leads to the non-dismissal of employees, and consequently the lack resources and costs adjustment. Therefore, with a higher number of employees, the costs of deescalating the level of activity stickiness will be higher. In their research, they looked into the effect of these two factors on cost stickiness, concluding that these factors have a positive effect on the level of adjusted costs at the firm level.

Cost structure varies significantly in diverse industries. For example, according to Elie (1991), the ratio of cost to sales is 5\% in the coal industry and 66\% in pharmaceutical product industry. Subramaniam et al. (2003) concluded that the highest rate of cost stickiness belonged to manufacturing companies followed by service and commercial companies. In contrast, they did not observe any sign of asymmetric cost behavior in financial companies. Anderson et al. (2004) investigated cost behavior in service companies, reporting the absence of any sticky costs in the retail sector, while the entertainment sector had the highest cost stickiness. According to their research, not only the degree of cost stickiness varies in different industries, but also the factors that provoke cost sticky behavior may exert divergent effects in each industry. They reported that, assets, staff and the prospect of improved sales had no effect on the degree of cost stickiness in the entertainment sector; while these factors had an undeniable impact on the degree of service costs in the hotel and restaurant industry.

Firm characteristics that could affect cost stickiness are, asset intensity, employee intensity, redundant operational capacity, and optimistic of management. The intensity of asset and 
employee, as discussed above, not only affected by industry type but also the firm-specific features have a significant effect on them.

Banker et al. (2006a) verified the relationship between utilized capacity and sticky cost behavior, attempting to expand this concept. According to Anderson et al. (2003), managers' expectations of the company's future performance play a pivotal role in adjustment/ nonadjustment of the company's resources.

In another study, Banker et al. (2011d) used indices of managerial optimism and pessimism to offer more empirical evidence for their argument, contending that managers' expectations are a determinant of cost behavior. Banker et al. (2011d) found that if these indicators transmit clear and continuous positive signals about the future of the company, the degree of cost stickiness will increase, but if conflicting or negative signals are sent, cost stickiness will plunge. In another study, Banker et al. (2011c) tested the model of Banker et al. (2011d) on an international sample, and their findings ratifying the above outcomes for most of countries.

Overall, the existing literature and theoretical foundations present strong evidence for stickiness in diverse types of costs in different years, industries, and companies. The research literature offers various reasons for cost stickiness, including managers' optimism and pessimism about sales prospects, earnings management, the nature of costs (in terms of controllability and uncontrollability), government regulations, technology level, employment protection laws and systems of, which can affect the degree of cost stickiness. 


\subsection{Hypothesis Development}

A variety of factors can influence the EFA. According to previous research [Weiss (2010), Cifitci and Salama (2018)] asymmetric cost behavior is one of the main factors affecting the EFA. Weiss (2010) contends that there is a negative relationship between cost stickiness and EFA. He states that sticky companies tend to forecast low future earnings, which explain the higher errors in projection of future earnings. Cifitci et al. (2016) argue that if analysts can fully understand cost behavior, no systematic relationship will be observed between cost behavior and EFE. On the other hand, if analysts fail to take cost stickiness into account in their forecasts, the degree of EFE will be significantly different at the time of declining and rising demand. Cifitci and Salama (2018) revealed a positive relationship between cost stickiness and EFE, because managers and analysts do not consider adverse consequences of cost stickiness in earnings forecast. If financial analysts are accurate in estimating variable costs or cost stickiness, the EFE should be symmetrical with the abnormal sales (desirable or undesirable). They stated that accurate cost forecast has a significant impact on the EFA. Therefore, according to the above, it can be stated that the degree of cost stickiness is one of the major factors that can influence the EFA and if financial analysts and managers fail to account for the degree of cost stickiness in their forecasts, they may have more mistake in earnings prediction. Based on the above, by separating the costs and analyzing the behavior of each of them, we can have a comprehensive analysis. Based on previous research, it is expected that the stickiness intensity of different types of costs will be different and have a variety effects on the EFA. Therefore, the first research hypothesis is developed as follows: 


\section{H1: SG\&A and COGS stickiness have a different effect on EFA.}

However, since the sources of cost stickiness are different and triggered by year, industry and firm-specific events and circumstances, we expect that the impact of each of these sources on the EFA be different. Forecasting and controlling events of each year, and identifying the firm-specific features is more complicates than other stickiness sources.

Therefore, the greater the impact of each sources on $S G \& A$ and $C O G S$ stickiness, the lower the EFA. Hence, the second hypothesis is expressed as follows:

H2: Each source of SG\&A and COGS stickiness has a different effect on EFA.

\section{Research Design}

\subsection{Separation of cost stickiness sources}

The degree of cost stickiness will be measured using the model of Anderson et al. (2003) according to model (1).

Model (1):

$$
\log \left(\frac{\operatorname{Cost}_{\mathrm{f}, \mathrm{t}}}{\operatorname{Cost}_{\mathrm{f}, \mathrm{t}-1}}\right)=\mathrm{B}_{0}+\mathrm{B}_{1} \cdot \log \left(\frac{\operatorname{Sales}_{\mathrm{f}, \mathrm{t}}}{\operatorname{Sales}_{\mathrm{f}, \mathrm{t}-1}}\right)+\mathrm{B}_{2} \cdot \text { DD. Log }\left(\frac{\operatorname{Sales}_{\mathrm{f}, \mathrm{t}}}{\operatorname{Sales}_{\mathrm{f}, \mathrm{t}-1}}\right)+\mathrm{e}_{\mathrm{f}, \mathrm{t}}
$$

As noted by Anderson et al. (2003), "If sales revenue rises, the dummy variable of sales decrease $(D D)$ will be zero. Thus, coefficient $B_{1}$ shows an increase in costs as a result of a $1 \%$ rise in sales revenue. Moreover, since the coefficient of the dummy variable of sales is equal to 1 when revenue decrease, the sum of coefficients $B_{1}+B_{2}$ denotes the percentage reduction in costs as a result of $1 \%$ reduction in sales revenue.

In sticky cases, the percentage of increase in costs during revenue growth period will be greater than the percentage of decrease in costs during revenue decrement. In other words, we will have $B_{1}>0, B_{2}<0\left(B_{1}+B_{2}<B_{1}\right)$. If costs are anti-sticky, $B_{1}>0$ and $B_{2}>0$, in which case 
$B_{1}+B_{2}>B_{1}$. It indicates that for $1 \%$ change in sales, the costs reduction will be greater than the rising costs.

We use three steps to separate the stickiness sources as follow. First, model (1) is run by all observations and overall stickiness is calculated by $\mathrm{B}_{2}$ coefficient. The calculated coefficient $\left(B_{2}\right)$ is affected by year, industry and firm. Then to control the effects of year, model (1) is tested for each year and the coefficient $\mathrm{B}_{2}$ is calculated for each year $\left(B_{2, y}\right)$ that influenced by the effects of industry and company. Therefore, by comparing $B_{2, y}$ and $B_{2}$ the degree of relative stickiness of each year $\left(C S_{y}\right)$ can be calculated

Second, we use the previous calculated $B_{2, y}$ and then, to control the effects of industry, model (1) will be run for each industry in each year. When name the coefficient $B_{2, y, i}$ which is influenced by the effects of the company. Therefore, by comparing $B_{2, y, i}$ and $B_{2, y}$, the degree of relative stickiness of each industry in each year $\left(C S_{y, i}\right)$ is obtained.

Third, since the number of observations is limited to one to determine the relative stickiness of each firm; hence, it is impossible to test regression for a single data. However, for the homogeneity of calculations with previous steps, the degree of relative stickiness of each company can be obtained as follow. Supposed line $C S_{y, i}$ indicates the regression relationship of these points for a specific company in a given industry and year according to the model 1 that ran in industry-year level with the slope of $B_{2, y, i}$. We assume that the intercept illustrates factors, which are the same in all observations of that industry-year and the difference of each observation is related to the specific cost stickiness of that point. The slope of each point (such as F1) with a line $\left(L F_{(y, i, f)}\right)$ that originating from the intercept shows the total stickiness of that observation $\left(B_{y, i, f}\right)$. In a similar way to other sources of cost stickiness, the relative cost stickiness of each firm-year is divided by the total cost stickiness of each observation $\left(B_{y, i, f}\right)$ to 
$\mathrm{B}_{2, \mathrm{y}, \mathrm{i}}$ calculated. A summary of the points discussed in this section and the conceptual model of separation of cost stickiness sources are presented in Figure 1.

\begin{tabular}{|c|c|c|c|c|}
\hline Step & Sticky source & observations & Coefficient & Relative stickiness index \\
\hline--- & $\overline{---}$ & (1) Overall & $B_{2}$ & --- \\
\hline 1 & Year & (1) Annual & & $\longrightarrow \frac{B_{2, y}}{B_{2}}=C S_{y}$ \\
\hline 2 & Industry & (1) Industry-year & & $\rightarrow \frac{B_{2, y, i}}{B_{2 . y}}=C S_{y, i}$ \\
\hline 3 & Company & (4)single observation & $B_{2, y, i, f}$ & $\frac{B_{y, i, f}}{B_{2, y, i}}=C S_{y, i, f}$ \\
\hline
\end{tabular}

Figure 1 - Conceptual model of separating cost stickiness sources

\subsection{Testing Research Hypotheses}

According to previous research, multiple factors influence the EFA. To test the research hypotheses and explain how cost stickiness and its sources can reduce EFA, it is necessary to control other variables affecting EFA. Therefore, to test the research hypotheses, we used the models proposed by Weiss (2010), Cifitci and Salama (2018) and Anderson et al. (2007). In this research, we used model 5 to test the first hypothesis ( $S \& A A$ and $C O G S$ stickiness); and model 8 for second hypothesis ( $S G \& A$ and $C O G S$ stickiness sources).

Model (5):

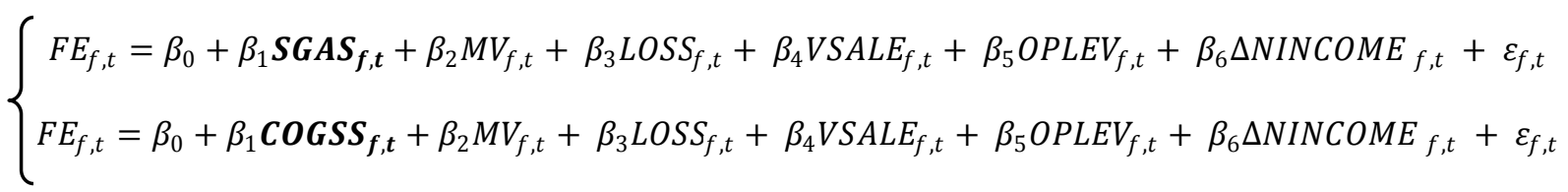


Model (6):

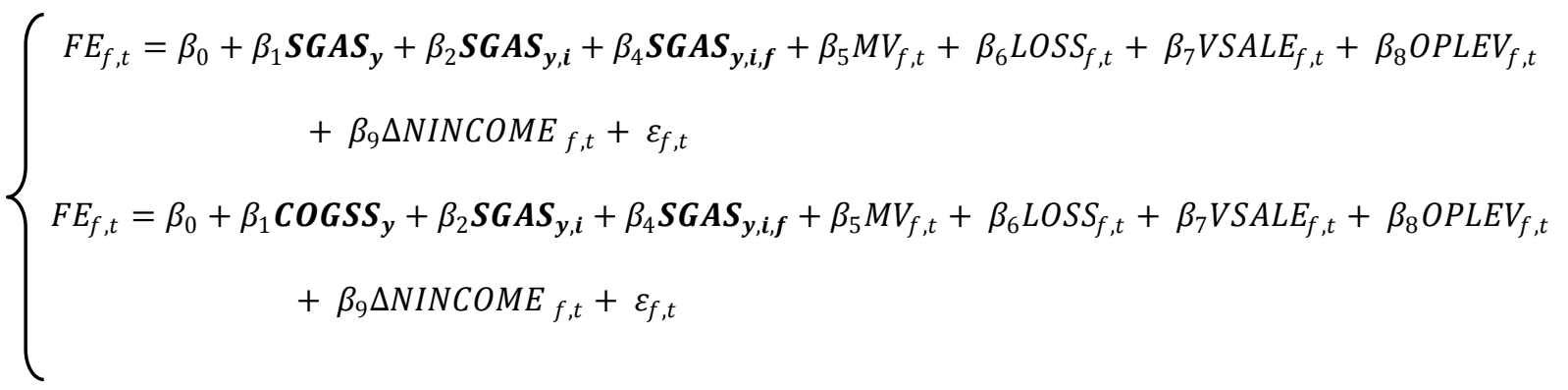

To verify the validity of the results, we calculated the cost stickiness by Anderson et al.'s model (2007) and confirming our first hypothesis results with them. The main reason for choosing this model is the ability of that to measure cost stickiness for each firm-year. We used their cost behavior proxies $\left(\operatorname{SGASignal}_{f, t}^{-} ; \operatorname{SGA~Signal}_{f, t}^{+}, \operatorname{COGS~Signal}_{f, t}^{-}, \operatorname{COGS~Signal}_{f, t}^{+}\right)$and substituted them in model 5 with our proxy $\left(S G A_{f, t} \& C O G S_{f, t}\right)$ and obtained the model 7. The results of this model are comparable with model 5 for verifying our proposed measurement.

Model (7):

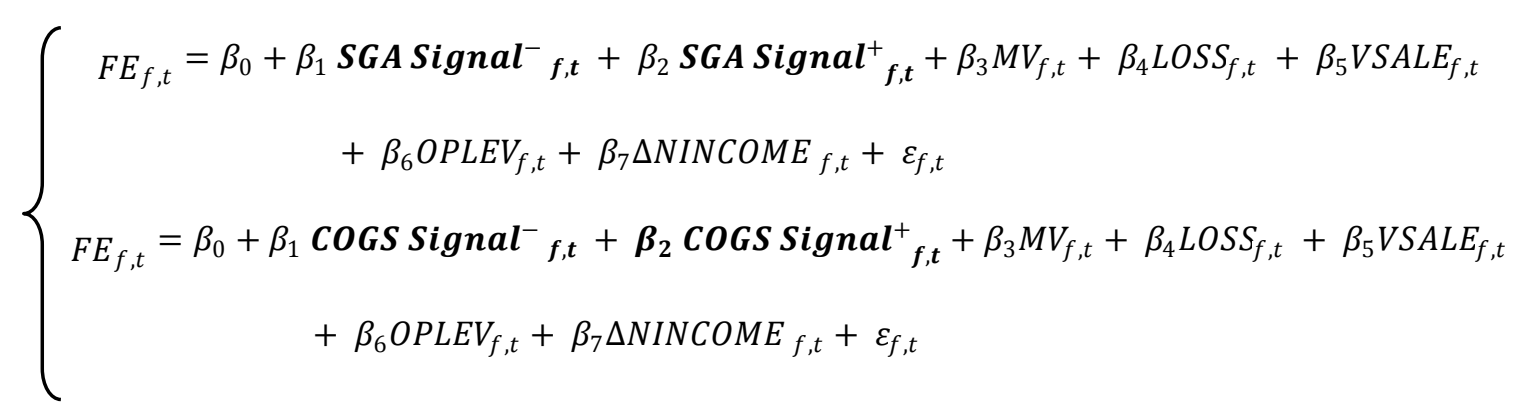

Table 1 provides descriptions of all variables. 
Table 1

Descriptions of variables (alphabetic)

\begin{tabular}{|c|c|}
\hline Variable & Description \\
\hline$\overline{A P}$ & Actual earnings per share (EPS) \\
\hline COGS & Total stickiness of cost of goods sold \\
\hline $\operatorname{COGSS}_{y}$ & $\begin{array}{l}\text { Relative COGS stickiness for each year when sales decrease and } 0 \text { otherwise, similar to Anderson et al } \\
\text { (2007). }\end{array}$ \\
\hline $\mathrm{COGSS}_{, i}$ & $\begin{array}{l}\text { Relative industry-year COGS stickiness when sales decrease and } 0 \text { otherwise, similar to Anderson et al } \\
\text { (2007). }\end{array}$ \\
\hline $\operatorname{COGSS}_{i, t}$ & $\begin{array}{l}\text { Relative firm-industry-year COGS stickiness when sales decrease and } 0 \text { otherwise, similar to Anderson et al } \\
\text { (2007). }\end{array}$ \\
\hline Decrease_Dummy & $\begin{array}{l}\text { The dummy variable takes the value of } 1 \text { when sales revenue decreases between period } t-1 \text { and } t \text {, and } 0 \\
\text { otherwise. }\end{array}$ \\
\hline$F P$ & Management earnings per share (EPS) forecasts \\
\hline \multirow[t]{2}{*}{$F E$} & The absolute forecast errors. \\
\hline & $F E_{f, t}=\left|\frac{\left(A P_{f, t}-F P_{f, t}\right)}{F P_{f, t}}\right|$ \\
\hline LOSS & Dummy variable that equals 1 if the reported earnings are negative and 0 otherwise. \\
\hline$M V$ & Logarithm of market value of equity + Liabilities \\
\hline$\triangle N I N C O M E$ & Indicator variable that equals 1 if the change in earnings from the prior year is positive, and 0 otherwise \\
\hline OPLEV & Ratio of gross income (sales, minus COGS) and sales \\
\hline Sale & Total revenue \\
\hline$S G A S$ & Total stickiness selling, general, and administrative costs \\
\hline$S G A S_{y}$ & $\begin{array}{l}\text { Relative SG\&A of cost stickiness for each year when sales decrease and } 0 \text { otherwise, similar to Anderson } \\
\text { et al (2007). }\end{array}$ \\
\hline$S G A S_{y, i}$ & $\begin{array}{l}\text { Relative industry-year SG\&A cost stickiness when sales decrease and } 0 \text { otherwise, similar to Anderson et al } \\
\text { (2007). }\end{array}$ \\
\hline$S G A S_{y, i, t}$ & $\begin{array}{l}\text { Relative firm-industry-year SG\&A cost stickiness when sales decrease and } 0 \text { otherwise, similar to Anderson } \\
\text { et al (2007). }\end{array}$ \\
\hline \multirow[t]{3}{*}{ SGA Signal ${ }^{-}$} & The SGA cost signal (cost stickiness) of each firm-year when sales decrease and 0 otherwise. \\
\hline & The negative SGA cost signal based on Anderson et al.'s model (2007) is calculated as follows: \\
\hline & SGA Signal ${ }^{-}=\frac{\operatorname{COST}_{i, t}}{\operatorname{SALES}_{i, t}}-\frac{\operatorname{COST}_{i, t-1}}{\operatorname{SALES}_{i, t-1}}$ \\
\hline \multirow[t]{3}{*}{ SGA Signal $^{+}$} & The SGA cost signal ${ }^{+}$of each firm-year when sales increase and 0 otherwise. \\
\hline & The positive SGA cost signal based on Anderson et al.'s model (2007) is calculated as follows:: \\
\hline & $\operatorname{SGASignal}^{+}=\frac{\operatorname{COST}_{i, t}}{\operatorname{SALES}_{i, t}}-\frac{\operatorname{COST}_{i, t-1}}{\operatorname{SALES}_{i, t-1}}$ \\
\hline
\end{tabular}


The negative COGS signal based on Anderson et al. 's model (2007) is calculated as follows:

$\operatorname{COGS~Signal}^{-}=\frac{\operatorname{COST}_{i, t}}{\operatorname{SALES}_{i, t}}-\frac{\operatorname{COST}_{i, t-1}}{\operatorname{SALES}_{i, t-1}}$

COGS Signal ${ }^{+} \quad$ The COGS signal ${ }^{+}$of each firm-year when sales increase and 0 otherwise.

The positive COGS signal based on Anderson et al. 's model (2007) is calculated as follows::

$\operatorname{COGS~Signal}^{+}=\frac{\operatorname{COST}_{i, t}}{\operatorname{SALES}_{i, t}}-\frac{\operatorname{COST}_{i, t-1}}{\operatorname{SALES}_{i, t-1}}$

VSALE The percentage change of sales to previous year.

This table defines the main variables.

\subsection{Description of Data}

Our sample includes all industrial firms from 2013 to 2018. Table 2 describes industry information. The sample was chosen according to the first two-digit SIC-Code ${ }^{2}$ industry, which displays the code of identifying the major industry group. Since regression model must be fitted in each industry-year to compute the cost stickiness in each industry-year. We also exclude firm-year observations in the financial services industry due to the disparity of financial report interpretations between these industries and other industries (Subramanyam, 1996).

Table 2

Industry Information

\begin{tabular}{lc}
\hline & Observation \\
\hline Motor Vehicles & 152 \\
Mineral Mining & 143 \\
Chemical & 193 \\
Food & 138 \\
Base Metals & 148 \\
Building & 160 \\
Pharmaceuticals & 146 \\
\hline Total & 1080 \\
\hline
\end{tabular}

\footnotetext{
${ }^{2}$ Standard Industrial Classification
} 
Table 3 describes our sample selection procedure. Our sample consists of all companies listed on the Tehran Stock Exchange (TSE) ${ }^{3}$ from 2013-2018. We trimmed the data to eliminate extreme observations by removing observations where the value of any variable was in the top or bottom 0.5 percent of its distribution (Chen \& Dixon, 1972). The final sample contains 1080 firm-year observations from 2014 to 2018.

Table 3

Sample selection procedures

\begin{tabular}{lc}
\hline & Observation \\
\hline All companies listed on the TSE from 2013 to 2018 & 2219 \\
Financial industry companies & 966 \\
Firms with insufficient information & 173 \\
\hline Final sample & 1080 \\
\hline
\end{tabular}

Table (4) demonstrates descriptive statistics in three columns (low EFE, High EFE, and all sample data). The low and high EFE distinguished by the median static. By comparing the average SGAS, COGSS, and their resources in the two groups, it can be stated that $S G A S$ and COGS, year origin of stickiness, industry and firm source are higher in high EFE conditions.

\footnotetext{
${ }^{3}$ The TSE is Iran's largest capital market. For detailed information about the TSE, refer to http://www.TSE.ir/.
} 
Table 4

Descriptive statistics of the full sample

\begin{tabular}{|c|c|c|c|c|c|c|}
\hline \multirow{2}{*}{ Variables } & \multicolumn{2}{|c|}{ low EFE } & \multicolumn{2}{|c|}{ High EFE } & \multicolumn{2}{|c|}{ All Sample Data } \\
\hline & $\mathbf{N}$ & Mean & $\mathbf{N}$ & Mean & $\mathbf{N}$ & Mean \\
\hline$F E$ & 540 & 0.356 & 540 & 2.005 & 1080 & 0.873 \\
\hline$S G A S$ & 540 & 0.010 & 540 & 0.233 & 1080 & 0.110 \\
\hline$S G A S_{y}$ & 540 & 0.240 & 540 & 0.354 & 1080 & 0.298 \\
\hline$S G A S_{y, i}$ & 540 & 0.112 & 540 & 0.157 & 1080 & 0.121 \\
\hline$S G A S_{y, i, f}$ & 540 & 0.295 & 540 & 0.340 & 1080 & 0.314 \\
\hline COGSS & 540 & 0.187 & 540 & 0.430 & 1080 & 0.199 \\
\hline $\operatorname{COGSS}_{y}$ & 540 & 0.314 & 540 & 0.528 & 1080 & 0.403 \\
\hline $\operatorname{coGSS}_{y, i}$ & 540 & 0.160 & 540 & 0.232 & 1080 & 0.199 \\
\hline $\operatorname{CoGSS}_{y, i, f}$ & 540 & 0.361 & 540 & 0.775 & 1080 & 0.521 \\
\hline SGA Signal & 540 & 0.004 & 540 & 0.009 & 1080 & 0.021 \\
\hline SGA Signal ${ }^{+}$ & 540 & -0.003 & 540 & -0.0001 & 1080 & -0.002 \\
\hline SGA Signal & 540 & 0.009 & 540 & 0.011 & 1080 & 0.034 \\
\hline SGA Signal ${ }^{+}$ & 540 & 0.0002 & 540 & -0.024 & 1080 & -0.005 \\
\hline$M V$ & 540 & 8.044 & 540 & 7.819 & 1080 & 7.935 \\
\hline$V S A L E$ & 540 & 0.084 & 540 & 0.082 & 1080 & 0.081 \\
\hline OPLEV & 540 & 0.284 & 540 & 0.221 & 1080 & 0.253 \\
\hline$\triangle N I N C O M E$ & 540 & -0.132 & 540 & -0.441 & 1080 & -0.257 \\
\hline
\end{tabular}

\section{Estimation Results}

\subsection{Separation of Cost stickiness sources}

To separating the cost stickiness sources we apply model (1) three times, first with all observations that results showed on table 5 , second for each year, and third for each industryyear (table 6), and then calculated relative stickiness of years and industries (table 6). 
Table 5

Results of Regressing Changes in Costs on Changes in Sales Revenue for the 5-Year Period 2014-2018

\section{Panel A: SG\&A}

\begin{tabular}{|c|c|c|c|}
\hline Independent variable & Exp. sign & Coef & p-value \\
\hline $\left.\log _{\left(\frac{\text { Sales }_{f, t}}{\text { Sales }_{f, t-1}}\right.}\right)$ & + & $\begin{array}{c}1.088 \\
(21.49)\end{array}$ & 0.000 \\
\hline DD. Log $\left(\frac{\text { Sales }_{f, t}}{\text { Sales }_{f, t-1}}\right)$ & - & $\begin{array}{l}-0.361 \\
(-6.44)\end{array}$ & 0.000 \\
\hline Constant & & $\begin{array}{l}0.003 \\
(0.47)\end{array}$ & 0.637 \\
\hline $\begin{array}{l}\text { Adjusted } R \text { Square } \\
\text { Observation }\end{array}$ & $\begin{array}{l}76.40 \% \\
1080\end{array}$ & & \\
\hline
\end{tabular}

Panel B: COGS

\begin{tabular}{|c|c|c|c|}
\hline Model (1): $\log \left(\frac{\operatorname{cog}_{f, t}}{\operatorname{coG} S_{f, t-1}}\right)$ & $=B_{0}+B_{1} \cdot \log$ & $\left(\frac{\text { Sales }_{f, t}}{\text { sales }_{f, t-1}}\right)+B_{2} \cdot$ DD. Log & $\left(\frac{\text { Sales }_{f, t}}{\text { sales } f, t-1}\right)+e_{f, t}$ \\
\hline Independent variable & Exp. sign & Coef & p-value \\
\hline $\log \left(\frac{\text { Sales }_{f, t}}{\text { Sales }_{f, t-1}}\right)$ & + & $\begin{array}{l}1.160 \\
(3.79)\end{array}$ & 0.000 \\
\hline$D^{D D . L o g}\left(\frac{\text { Sales }_{f, t}}{\text { Sales }_{f, t-1}}\right)$ & - & $\begin{array}{l}-0.743 \\
(-2.36)\end{array}$ & 0.021 \\
\hline Constant & & $\begin{array}{l}-0.007 \\
(-0.54)\end{array}$ & 1.032 \\
\hline Adjusted R Square & $67.15 \%$ & & \\
\hline Observation & 1080 & & \\
\hline
\end{tabular}

The coefficient $\beta_{2}$ is a negative estimate that indicates the degree of stickiness in all observations, which is equal to -0.361 in $S G \& A$ and equal to -0.743 in $C O G S$.

In table 6 , Cost Stickiness $\left(B_{2, y}\right)$ showed the stickiness of each year, and could be influenced by the effects of industry and company. By comparing $B_{2}$ and $B_{2, y}$, the degree of relative stickiness related to each year was calculated, the results of which are presented in table 6 . 


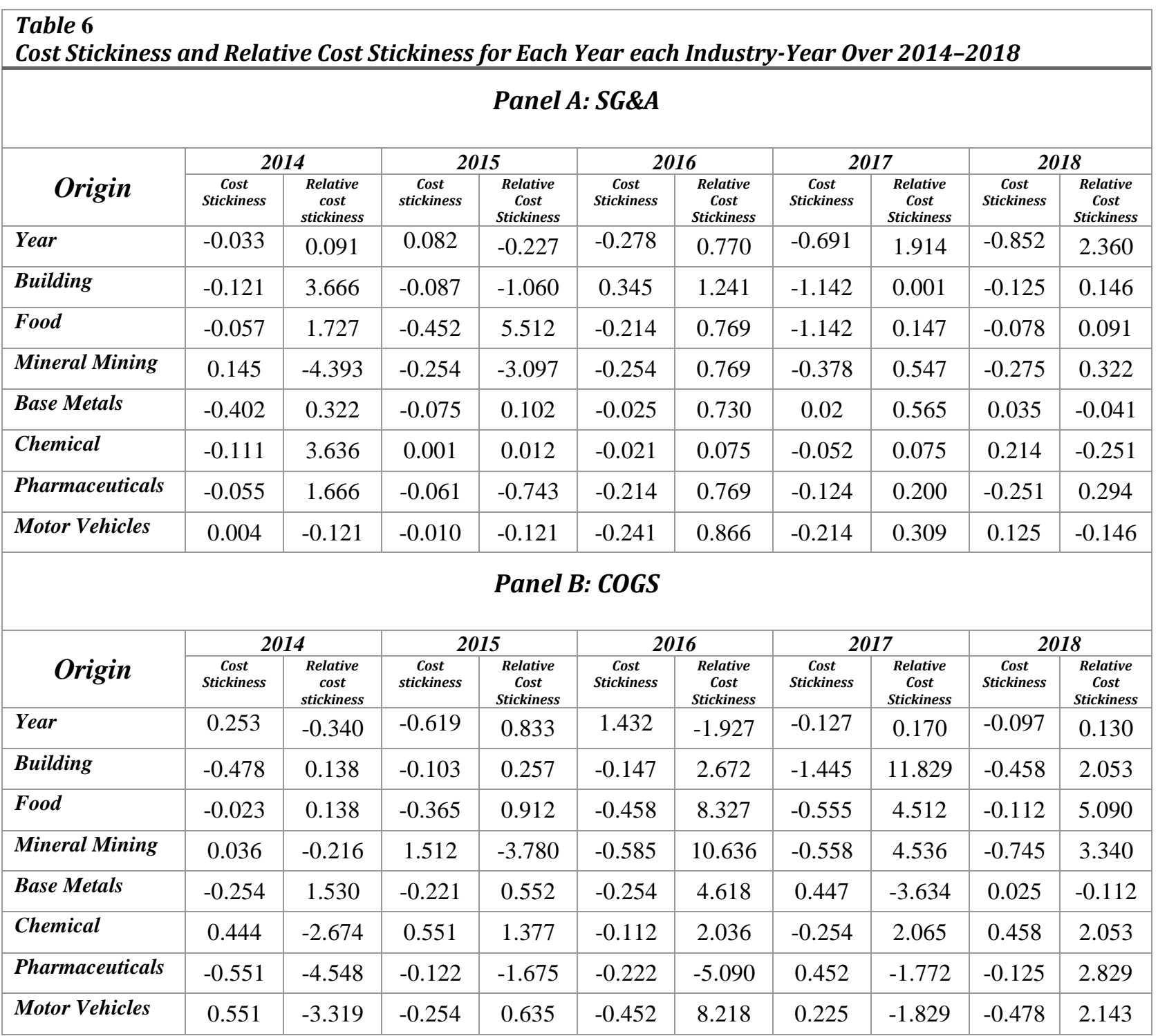

As depicted in Table (6), the relative stickiness in $S G \& A$ was the highest in 2017 and 2018, which indicates the strong effects of the events in 2017 and 2018 on the degree of stickiness. The most important event of 2018 was the withdrawal of the United States from JCPOA ${ }^{4}$ and the imposition of new sanctions against Iran, which was a major hurdle to the production and export of many industries in Iran and cut its production capacity, so that companies faced significant unutilized resources.

\footnotetext{
${ }^{4}$ Joint Comprehensive Plan of Action
} 
Table 6 also represents the results of executing cost stickiness regression at the industry-year level. By comparing the cost stickiness coefficient of this model with the results of cost stickiness, the relative effects of industry on cost stickiness can be determined.

\subsection{Testing Hypothesis}

\subsubsection{SG\&A and COGS stickiness and EFA (H1)}

The test results of first hypothesis are presented in table 7 and 8 . The hypothesis test results are reported in two columns of these tables; the first column is based on our model (model 5) and the second column is based on Anderson et al (2007) model (model 6). As shown by the results in table 7 , the $S G \& A$ stickiness of each company is positively and significantly correlated with the EFE and the hypothesis is confirmed with both models. The results calculated by our model illustrates a stronger relationship between cost stickiness and EFE. and significant (t-statistic $=2.09$ ), suggesting that the stickiness of $S G \& A$ is directly and significantly related to the EFE.

As shown by the results in table 12 , the COGS stickiness of each company is positively and significantly correlated with the EFE and the hypothesis is confirmed with both models. The results calculated by our model illustrates a stronger relationship between cost stickiness and EFE. 
Table 7

Regression Coefficient of Management Forecast Error on SG\&A Stickiness.

\begin{tabular}{|c|c|c|}
\hline \multicolumn{2}{|l|}{$\begin{array}{l}\text { Regression Model (7): } \\
\qquad F E_{f, t}=\beta_{0}+\beta_{1}\end{array}$} & $\begin{array}{l}\text { Regression Model (10): } \\
\text { FE }_{f, t}=\beta_{0}+\beta_{1} \text { SGAS Signal }_{f, t}^{-}+\beta_{2} \text { SGA Signal }_{f, t}^{+}+\beta_{3} M V_{f, t}+\beta_{4} \text { LOSS }_{f, t}++\beta_{5} \text { VSALE }_{f, t}+\beta_{6} \text { OPLEV }_{f, t}+ \\
\beta_{7} \Delta N I N C O M E_{f, t}+\varepsilon_{f, t}\end{array}$ \\
\hline & & \\
\hline Independent variable & Model (5) & Model (6) \\
\hline$S G A S$ & $\begin{array}{l}4.152 * * * \\
(4.20)\end{array}$ & \\
\hline SGA Signal- & & $\begin{array}{l}19.03 * * \\
(2.09)\end{array}$ \\
\hline SGA Signal ${ }^{+}$ & & $\begin{array}{l}-1.932 \\
(-019)\end{array}$ \\
\hline$M V$ & $\begin{array}{l}-0.125^{* *} \\
(-2.04)\end{array}$ & $\begin{array}{l}-1.587 * * \\
(-2.08)\end{array}$ \\
\hline LOSS & $\begin{array}{c}0.115^{*} \\
(2.31)\end{array}$ & $\begin{array}{l}9.976 * * \\
(2.92)\end{array}$ \\
\hline$V S A L E$ & $\begin{array}{l}-0.181^{*} \\
(-1.96)\end{array}$ & $\begin{array}{l}-0.113 \\
(-1.38)\end{array}$ \\
\hline OPLEV & $\begin{array}{l}0.251 * \\
(1.88)\end{array}$ & $\begin{array}{l}0.958 \\
(0.41)\end{array}$ \\
\hline$\triangle N I N C O M E$ & $\begin{array}{r}0.152 \\
(0.44)\end{array}$ & $\begin{array}{l}0.059 * * \\
(-2.099)\end{array}$ \\
\hline Constant & $\begin{array}{c}7.251 \\
(10.03)\end{array}$ & $\begin{array}{l}-9.941 \\
(-2.00)\end{array}$ \\
\hline $\begin{array}{l}\text { Adjusted R-Square } \\
\text { Number of observations }\end{array}$ & $\begin{array}{l}27.25 \% \\
1080\end{array}$ & $\begin{array}{l}25.72 \% \\
1080\end{array}$ \\
\hline
\end{tabular}

Significant level: $* * * 1 \%, * * 5 \%, * 10 \%$

The $S G \& A$ stickiness coefficient estimated by our model was significantly positive $\left(\beta_{1}=\right.$ 4.152, t-statistics $=4.20$ ), which shows that the stickiness of $S G \& A$ is directly and significantly related to EFE, so that with one-unit increase in the $S G \& A$ stickiness, the EFE rises by 4.152 . The coefficient of $S G \& A$ estimated by Anderson et al (2007) model was positive $\left(\beta_{1}=19.03\right)$. 
The COGS stickiness coefficient estimated by our model was significantly positive $\left(\beta_{1}=\right.$ 6.165, t-statistics $=2.45$ ), which shows that the stickiness of COGS is directly and significantly related to EFE, so that with one-unit increase in the COGS stickiness, the EFE rises by 6.165 .

Table 8

Regression Coefficient of Management Forecast Error on COGS Stickiness.

Regression Model (5):

$F E_{f, t}=\beta_{0}+\beta_{1} \operatorname{COGSS}_{f, t}+\beta_{2} M V_{f, t}+\beta_{3} L_{O S S} S_{f, t}+\beta_{4} \operatorname{VSALE}_{f, t}+\beta_{5}$ OPLEV $_{f, t}+\beta_{6} \Delta N I N C O M E_{f, t}+\varepsilon_{f, t}$

Regression Model (6):

$\mathrm{FE}_{f, t}=\beta_{0}+\beta_{1}$ COGA Signal $_{f, t}^{-}+\beta_{2}$ COGS Signal $_{f, t}^{+}+\beta_{3}$ MV $_{f, t}+\beta_{4}$ LOSS $_{f, t}++\beta_{5}$ VSALE $_{f, t}+\beta_{6}$ OPLEV $_{f, t}+$ $\beta_{7} \Delta N I N C O M E_{f, t}+\varepsilon_{f, t}$

\begin{tabular}{|c|c|c|}
\hline \multicolumn{3}{|c|}{$\begin{array}{c}\text { Coefficient Estimates } \\
\text { (t-statistics) }\end{array}$} \\
\hline Independent variable & Model (5) & Model (6) \\
\hline COGSS & $\begin{array}{l}6.165^{* *} \\
(2.45)\end{array}$ & \\
\hline COGS Signal & & $\begin{array}{l}11.866^{* *} \\
(2.24)\end{array}$ \\
\hline COGS Signal $^{+}$ & & $\begin{array}{l}-5.532 * * \\
(-2.32)\end{array}$ \\
\hline$M V$ & $\begin{array}{l}-0.254 * * \\
(-2.11)\end{array}$ & $\begin{array}{l}-1.212 * * \\
(-2.28)\end{array}$ \\
\hline LOSS & $\begin{array}{l}2.031^{* *} \\
(2.21)\end{array}$ & $\begin{array}{l}7.976^{* *} \\
(2.52)\end{array}$ \\
\hline VSALE & $\begin{array}{l}-1.112 \\
(-1.08)\end{array}$ & $\begin{array}{l}-0.545 \\
(-1.45)\end{array}$ \\
\hline OPLEV & $\begin{array}{r}0.087 \\
(0.88)\end{array}$ & $\begin{array}{l}0.452 \\
(0.021)\end{array}$ \\
\hline$\triangle N I N C O M E$ & $\begin{array}{r}0.221 \\
(0.15)\end{array}$ & $\begin{array}{r}0.121 \\
(0.10)\end{array}$ \\
\hline Constant & $\begin{array}{l}8.11 * * \\
(3.03)\end{array}$ & $\begin{array}{l}-11.491 * * \\
(-3.00)\end{array}$ \\
\hline $\begin{array}{l}\text { Adjusted } R \text {-Square } \\
\text { Number of observations }\end{array}$ & $\begin{array}{l}20.96 \% \\
1080\end{array}$ & $\begin{array}{l}18.25 \% \\
1080\end{array}$ \\
\hline nt level: $* * * 1 \%$, * & & \\
\hline
\end{tabular}


The coefficient of COGS estimated by Anderson et al (2007) model was positive ( $\beta_{1}=$ 11.866) and significant (t-statistic $=2.24)$, suggesting that the stickiness of COGS is directly and significantly related to the EFE.

\subsubsection{SG\&A and COGS stickiness sources and EFE (H2)}

The test results of the second hypothesis are presented in Table 9 and 10. The results illustrate that the relative stickiness of each year and each company in both SG\&A and COGS is significantly related with the EFE, while there is no significant relationship between the stickiness of each industry and EFE.

The estimated coefficient of $S G \& A$ relative stickiness in each year was positive $\left(\beta_{1}=0.145\right)$ and significant (t-statistic $=3.21)$, indicating that the relative stickiness in each year is directly and significantly correlated with EFE. That is, with a one-unit increase in the relative stickiness of each year, the EFE rises by 0.145 units. The estimated coefficient of relative stickiness in each industry-year is positive $\left(\beta_{2}=0.050\right)$ and not significant $(\mathrm{t}$-statistic $=0.02)$, demonstrating that the average relative stickiness of each industry did not induce a significant forecast error. In the company level, the estimated coefficient of relative stickiness was positive $\left(\beta_{3}=0.24\right)$ and significant $(\mathrm{t}$-statistic $=2.00)$, suggesting that the relative stickiness of each company has a direct and significant relationship with EFE. 
Table 9

Regression Coefficient of Management Forecast Error on the Sources of SG\&A Stickiness.

Regression Model (7):

$F E_{f, t}=\beta_{0}+\beta_{1} S G A S_{y}+\beta_{2} S G A S S_{y, i}+\beta_{3} S G A S S_{y, i, f}+\beta_{4} M V_{f, t}+\beta_{5} L_{O S S}, t+\beta_{6} V S A L E_{f, t}+$ $\beta_{7} O P L E V_{f, t}+\beta_{8} \Delta N I N C O M E_{f, t} \varepsilon_{f, t}$

\begin{tabular}{|c|c|}
\hline & $\begin{array}{c}\text { Coefficient Estimates } \\
\text { ( } t \text {-statistics })\end{array}$ \\
\hline Independent variables & Model (7) \\
\hline$S G A S S_{y}$ & $\begin{array}{l}0.145^{* * *} \\
(3.21)\end{array}$ \\
\hline$S G A S S_{y, i}$ & $\begin{array}{l}0.050 \\
(0.02)\end{array}$ \\
\hline$S G A S S_{y, i, f}$ & $\begin{array}{l}0.024 * * \\
(2.00)\end{array}$ \\
\hline$M V$ & $\begin{array}{l}-0.124 * * \\
(-2.40)\end{array}$ \\
\hline LOSS & $\begin{array}{l}0.142 \\
(0.18)\end{array}$ \\
\hline$V S A L E$ & $\begin{array}{r}0.010 \\
(0.12)\end{array}$ \\
\hline OPLEV & $\begin{array}{c}0.12 \\
(1.12)\end{array}$ \\
\hline$\triangle N I N C O M E$ & $\begin{array}{r}-0.121 \\
(-5.42)\end{array}$ \\
\hline Constant & $\begin{array}{l}0.124 * * * \\
(10.37)\end{array}$ \\
\hline Adjusted R-Square & $8.31 \%$ \\
\hline Observation & 1080 \\
\hline
\end{tabular}

As shown by the results in table 10, the estimated coefficient of COGS relative stickiness in each year was positive $\left(\beta_{1}=0.121\right)$ and significant $(\mathrm{t}$-statistic $=2.09)$, indicating that the relative stickiness in each year is directly and significantly correlated with EFE. That is, with a one-unit increase in the relative stickiness of each year, the EFE rises by 0.121 units. The 
estimated coefficient of relative stickiness in each industry-year is positive $\left(\beta_{2}=0.003\right)$ and not significant $(\mathrm{t}$-statistic $=0.19)$, demonstrating that the average relative stickiness of each industry did not induce a significant forecast error.

Table 10

Regression Coefficient of Management Forecast Error on the Sources of COGS Stickiness.

Regression Model (7):

$F E_{f, t}=\beta_{0}+\beta_{1} \operatorname{COGSS}_{y}+\beta_{2} \operatorname{COGSS}_{y, i}+\beta_{3} \operatorname{COGSS}_{y, i, f}+\beta_{4} M V_{f, t}+\beta_{5} L_{0 S S_{f, t}}+\beta_{6} V_{S A L E}, t$ $\beta_{7} O P L E V_{f, t}+\beta_{8} \Delta N I N C O M E_{f, t} \varepsilon_{f, t}$

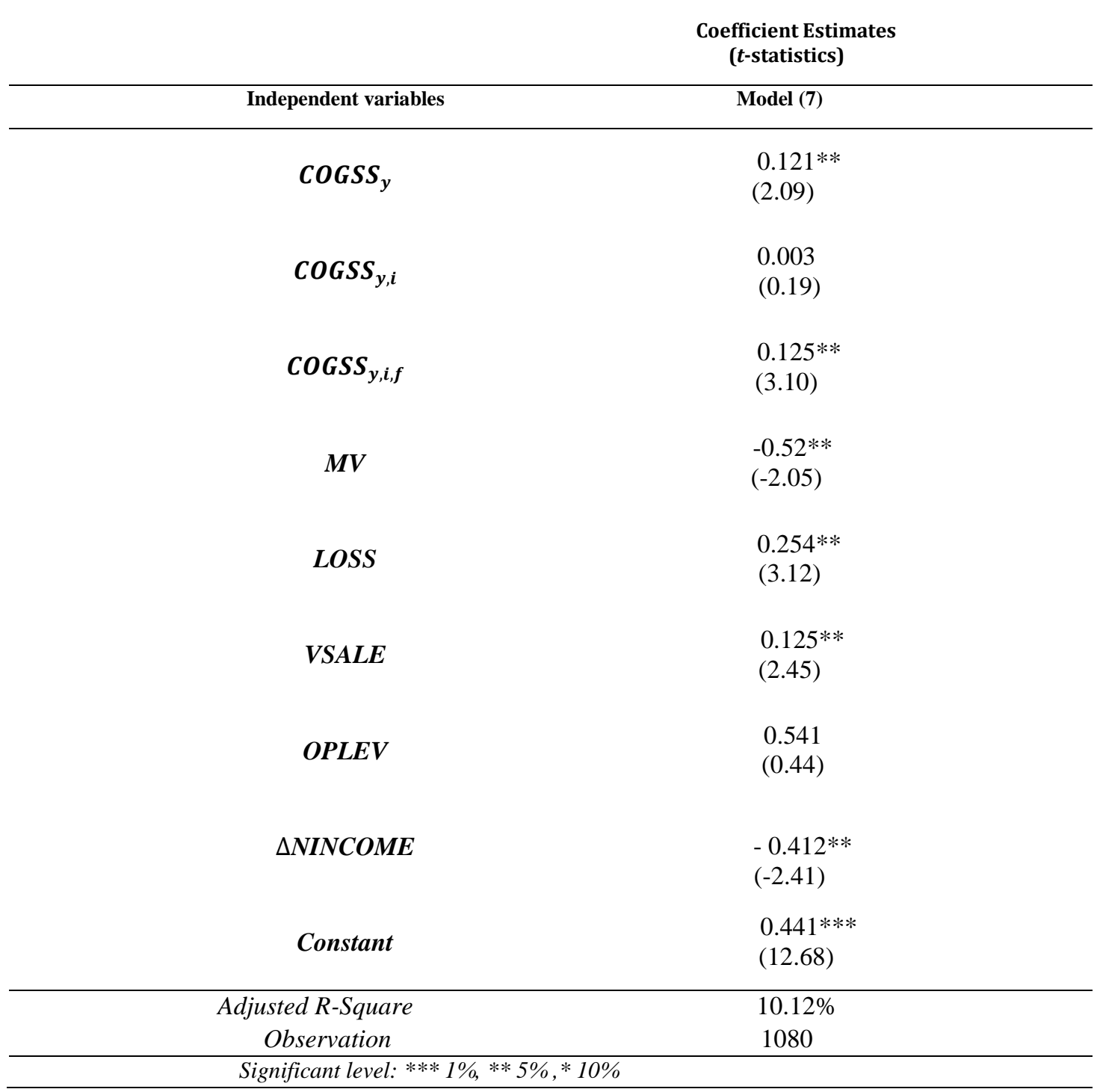


In the company level, the estimated coefficient of relative stickiness was positive $\left(\beta_{3}=\right.$ 0.125) and significant (t-statistic $=3.10)$, suggesting that the relative stickiness of each company has a direct and significant relationship with EFE.

The comparison results illustrate that the year and company sources, regardless of the cost category, affect the EFE. The results of this comparison are presented in Table 11.

\begin{tabular}{|c|c|c|c|}
\hline $\begin{array}{l}\text { Table 11 } \\
\text { Comparison of cost stickiness source coefficients. }\end{array}$ & Year-Specific & Industry-Specific & Firm-Specific \\
\hline Cost category & Characteristics & Characteristics & Characteristics \\
\hline \multirow{2}{*}{ SG\&A } & $\begin{array}{c}0.145^{* *} \\
(3.21)\end{array}$ & $\begin{array}{c}\text { (0.050 } \\
(0.02)\end{array}$ & $\begin{array}{c}\left(24^{* *}\right. \\
(2.00)\end{array}$ \\
\hline COGS & $0.121^{* *}$ & 0.003 & $0.125^{* *}$ \\
& $(2.09)$ & $(0.19)$ & $(3.10)$ \\
\hline
\end{tabular}

\section{Summary and Conclusion}

According to previous research, one of the major consequences of cost stickiness is its adverse impact on the EFA. In the present study, we further investigated this subject by examining the relationship between the stickiness of each source of cost stickiness and the EFA. In this study, we presented a method that not only separated the sources of cost stickiness, but also calculated cost stickiness for each year-company. Then, the effect of $S G \& A$ and $C O G S$ stickiness and all of their sources on the EFA was investigated. The results showed that the degree of $S G \& A$ and $C O G S$ stickiness has a negative and significant relationship with the EFA so that a higher degree of stickiness decreased the EFA.

Accordingly, investors, analysts, managers, and other users need to consider the consequences of total cost stickiness in forecasting future earnings and assessing the value of company so that they can estimate the future performance of the company with the least error. 
In addition, to further investigate the proposed method, each year-company stickiness was tested with the model of Anderson et al. (2007) and its effect on the EFA was explored. The results were aligned with those obtained from our proposed method. Findings also suggest that among the sources of cost stickiness, stickiness of each year and each company have a negative and significant effect on the EFA. It indicates that each year events and intraorganizational events have a greater effect on EFA compared to other sources of cost stickiness. Therefore, it can be contended that by separating the sources of cost stickiness and including them in earnings forecast models, a more accurate estimate of future earnings can be made. It is worth to note that the findings of this study are consistent with those reported by Weiss (2010), Cifitci et al. (2016), Cifitci and Salama (2018) and Banker and Chen (2006).

\section{References}

Anderson, M. C., R. D. Banker, and S. N. Janakiraman. (2003). Are Selling, General, and Administrative Costs "Sticky" "? Journal of Accounting Research,41(1), 47-63. https://doi.org/10.1111/1475-679X.00095

Anderson, M. C., R. D. Banker, L. Chen, and S. N. Janakiraman. (2004). Sticky Costs at Service Firms, Working paper, University of Texas at Dallas.

Anderson, M., Banker, R., Huang, R., \& Janakiraman, S. (2007). Cost Behavior and Fundamental Analysis of SG\&A Costs, Journal of Accounting, Auditing \& Finance, 22 (1), 1-28. https://doi.org/10.1177/0148558X0702200103

Awad, E. \& Awad, I. (2015). Economic growth and cost stickiness: evidence from Egypt, Journal of Financial Reporting and Accounting, 13 (1), 119-140. https://doi.org/10.1108/JFRA-06-2014-0052

Banker, Rajiv D. and Chen, Tony Lei, (2006). Labor Market Characteristics and Cross-Country Differences in Cost Stickiness, AAA 2007 Management Accounting Section (MAS) Meeting, Available at SSRN: https://ssrn.com/abstract=921419 or http://dx.doi.org/10.2139/ssrn.921419

Banker, R. D., and L. Chen. (2006b). Predicting Earnings Using a Model Based on Cost Variability and Cost Stickiness, The Accounting Review, 81(2), 285-307. https://doi.org/10.2308/accr.2006.81.2.285

Banker, R. D., D. Byzalov, and J. M. Plehn-Dujowich. (2011). Sticky Cost Behavior: Theory and Evidence, Working Paper, Temple University.

Banker, R. D., D. Byzalov, and L. T. Chen. (2011a). Impact of Labor Laws on Cost Behavior, Working paper, Temple University and Peking University.

Banker, R. D., D. Byzalov, and L. Chen. (2013). Employment protection legislation, adjustment costs and cross-country differences in cost behavior, Journal of Accounting and Economics, 55(1), 111-127. https://doi.org/ 10.1016/j.jacceco.2012.08.003.

Banker, R. D., R. Flasher, and D. Zhang. (2014). Strategic positioning and asymmetric cost behavior. Working paper, Temple University. 
Banker, R. D., D. Byzalov, M. Ciftci, and R. Mashruwala.(2014). The Moderating Effect of Prior Sales Changes on Asymmetric Cost Behavior, Journal of Management Accounting Research, 26(2), 221-242. https://doi.org/10.2308/jmar$\underline{50726}$

Calleja, K., M. Steliaros, and D. C. Thomas. (2006). A Note on Cost Stickiness: Some International Comparisons, Management Accounting Research, 17 (2), 127-140. https://doi.org/10.1016/j.mar.2006.02.001

Chen, C.X., Lu, H. and Sougiannis, T. (2012). The Agency Problem, Corporate Governance, and the Asymmetrical Behavior of Selling, General, and Administrative Costs, Contemporary Accounting Research, 29, $252-282$. https://doi.org/10.1111/j.1911-3846.2011.01094.x

Cheng, T. and Firth, M. (2000). An Empirical Analysis of the Bias and Rationality of Profit Forecasts Published in New Issue Prospectuses. Journal of Business Finance \& Accounting, 27, 423-446. https://doi.org/10.1111/1468-5957.00319

Ciftci, M., R, Mashruwala,., D,Weiss.(2016). Implications of Cost Behavior for Analysts' Earnings Forecasts. Journal of Management Accounting Research, 28(1), 57-80. https://doi.org/10.2308/jmar-51073

Ciftci, M \& M. Salama. (2018). Stickiness in Costs and Voluntary Disclosures: Evidence from Management Earnings Forecasts, Journal of Management Accounting Research, 30 (3), 211-234. https://doi.org/10.2308/jmar-51966

Dierynck, Bart and Renders, Annelies, (2009). Earnings Management Incentives and the Asymmetric Behavior of Labor Costs: Evidence from a Non-US Setting. AAA 2010 Management Accounting Section (MAS) Meeting Paper, Available at SSRN: https://ssrn.com/abstract=1441250 or http://dx.doi.org/10.2139/ssrn.1441250

Kama, I. and weiss, D. (2013). Do Earnings Targets and Managerial Incentives Affect Sticky Costs?, Journal of Accounting Research, 51, 201-224. https://doi.org/10.1111/j.1475-679X.2012.00471.x

Lee, W. J. \& Pittman, J. \& Saffar, W. (2020). Political Uncertainty and Cost Stickiness: Evidence from National Elections around the World, Contemporary Accounting Research, 17 (2), pp. 1107-1139. https://doi.org/10.1111/1911-3846.12547

Subramanyam, K. (1996). The Pricing of Discretionary Accruals, Journal of Accounting and Economics, 22 (1-3), $249-281$. https://doi.org/10.1016/S0165-4101(96)00434-X

Subramaniam, C. and Watson, M. Weidenmier. (2016).Additional Evidence on the Sticky Behavior of Costs, Advances in Management Accounting , 26, 275-305. https://doi.org/10.1108/S1474-787120150000026006.

Weiss, D. (2010). Cost Behavior and Analysts' Earnings Forecasts, The Accounting Review, 85(4), 1441-1471. https://doi.org/10.2308/accr.2010.85.4.1441 